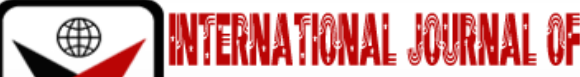

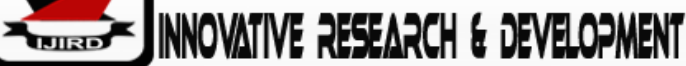

ISSN 2278-0211 (Online)

\section{Factors Influencing the Implementation of ICT-Based Innovations in the Primary Healthcare Subsector in Southwestern Nigeria}

\author{
Dr. Babatunde S. Asenuga \\ Lecturer, Department of Management Sciences \\ Wesley University Ondo, Nigeria
}

\begin{abstract}
:
This study assesses the factors influencing implementation of ICT-based Innovations in the primary healthcare sector in Southwestern Nigeria. The study covered 30 registered primary healthcare centres selected from Lagos, Ogun and Oyo States in Southwestern Nigeria using multistage sampling technique. Data were obtained using two sets of questionnaires along with interviews. The result using Principal Factor Analysis revealed that seven component factors were significant $(p<0.5)$ as factors that influence the implementation of ICT-based innovation in Southwestern Nigeria; these are: clarity of usage, clarity of policy, protecting lives, clarity of acceptance, quality, authority, energy requirement. The study concluded that implementation of ICT-based innovations in the Nigerian primary healthcare sector would be enhanced if the component factors highlighted could be adopted for future ICT-based innovation implementation
\end{abstract}

Keywords: ICT-based innovation, primary healthcare centres, Nigeria healthcare delivery

\section{Introduction}

Healthcare delivery in Nigeria is complex with numerous providers in both the public and private sectors. These private sector providers include community-based, religious and traditional as well as private healthcare providers forprofit and not-for-profit (Olakunde, 2012). Highly effective primary healthcare is known to keep individuals, families and communities healthy, however, primary healthcare presently has driven policy makers to be more concerns about accessibility, because primary healthcare is characterized by venerable healthcare workforce, increased prevalence of chronic diseases and the complexities of team-based contemporary practice.

Innovation development or acquisition is a positive step in enhancing the quality of healthcare in any healthcare system; however, to achieve the required effectiveness and efficiency of healthcare service delivery, the stage of innovation implementation must be handled with care and seriousness. Innovations have been seen by various international sponsors and locals in Africa as tools for different initiatives of technology transfer; yet, Poor innovation implementations is still relatively observed (Ika, Diallo, and Thuillier, 2010).

Innovations rate of failure is estimated to be $50 \%$ for World Bank in Africa; while $39 \%$ of innovations in World Bank were discovered in 2010 by Independent Evaluation Group (IEG) research to be unsuccessful (Ika et al., 2010). According to Kwak and Radler (2002), different organizations proffer managerial function as a result of flawed framing of innovation, inadequate management by stakeholder, slowness in starting up and identifying innovation, hindrances when implementing project, over budgeting, and lack of coordination.

However, it is globally known that one of the principal challenges with the introduction of ICT-based innovations or clinical guidelines typically is that users of the innovation do not use them automatically as developed and intended. This study assessed the factors influencing the implementation of ICT-based Innovations in the primary healthcare subsector.

\section{Literature Review}

\subsection{Determinants of Effective Implementation}

Drivers of effective implementation according to Weiner et al. (2009) and Sawang and Unsworth, (2011) in figure 1 can be categorized as follows: "evaluation and monitoring, financial resources, climate and culture of organisations, leadership skills, innovation's efficacy and top management style". Other authors have shown systematic deviation in their studies towards some factors such as the role the end-users and managers play are found to be significant in ensuring successful implementation of ICT-based innovation (Vaughan, 2001; Osei-Bryson et al., 2008). 
King (2002) argued that to achieve success in implementing ICT-based innovations, adoption of principles models of an organized process that distinguished engineering from alchemy must be seen a major component. It was argued further that involving end-users, defining statement of requirements clearly and support from top management forms part of the framework for measuring success (effectiveness) (King, 2002). King's recommendation is that the usage of existing resources must be optimal by the Management before engaging any financial commitment.

\subsubsection{Evaluation and Monitoring}

Evaluation is defined according to Montgomery and Zint (2010) as "the critical examination of a programme". Evaluation consists of the collection and analysing of various activities, characteristics and outcomes of programme information (Montgomery and Zint, 2010). Montgomery and Zint (2010) opined that the objective of evaluation to inform programming decisions is essential to improve the effectiveness of a programme.

Implementing ICT-based innovations requires substantial amount of human, financial and other resources. The sponsor of the innovation defines the characteristics of the innovation. Investing in these resources is very essential toward achieving the success of the innovation. Supervision according to Montgomery and Zint (2010) must be effective for an innovation to succeed.

\subsubsection{Financial Resource Motivation}

Several studies have shown that the greatest factor for slow uptake of ICT-based innovation in Africa is lack of funds (Klein et al., 2001; Ng'ethe, 2003). It is believed that one of the main determinants of innovation success is adequate financial resources (Studer, 2005). According to Studer (2005), it was observed that the need for operational support and the high cost of implementing ICT-based innovation were major setback to adopting electronic medical records (EMR). Finances are very important in acquiring ICT-based innovation (hardware and software), as well as training on how to use the ICT-based innovation and allowing the end-user have a good time to test the new ICT-based innovation (Macharia and Nyakwende, 2010).

\subsubsection{Organizational Culture}

Vaughan (2001) argued that involving users in system implementation is a practice that has a high correlation with system success. Peng and Kurnia (2010) supported the study of Lin and Shao (2000), which opined that involving end-users strongly when designing a system has three benefits: using the system is widened; the users accept the system; and users' satisfaction of the system is enhanced. These studies indicate that involving end-user is a key factor in enhancing the success of implementing ICT-based innovation.

According to Egbu et al. (2001) cited in Peansupap and Walker (2015), it is revealed that using an ICT-based innovation by end-users requires some major motivation. Peansupap and Walker's (2005) study further revealed that the characters and behaviour of user is the bases for the motivation for using ICT-based innovation; users with high selfconfidence who are eager to learn will likely use the introduced ICT-based innovations. Achieving success in implementing ICT-based innovations requires the involvement of end-users from the inception stage of the project and not to be used as rubber stamp of what is already in existence.

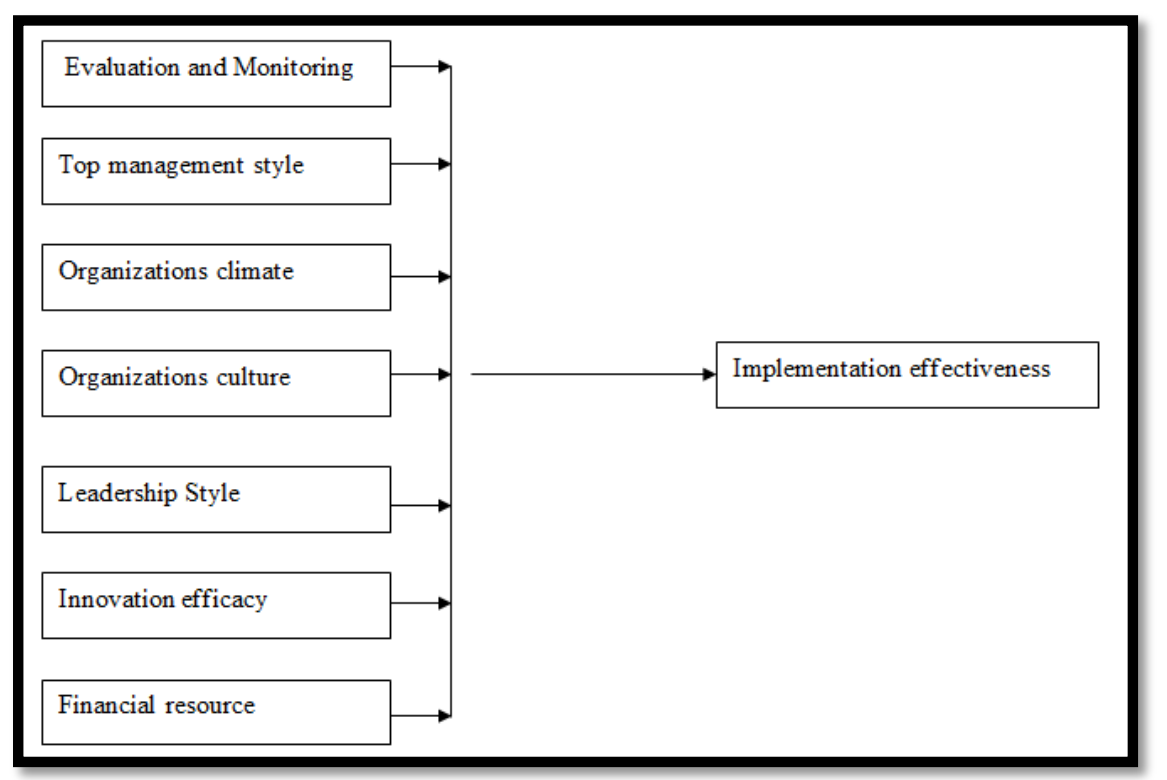

Figure 1: Theoretical Model in Determining Implementation Effectiveness Source: Weiner Et Al. (2009) and Sawang and Unsworth, (2011)

\subsubsection{Organisations' Climate}

Klein and Sorra (1996) argued that the contributions by various institutions practices and policies to the development of a positive organisational climate can promote the usage of an innovation. Klein and Sorra (1996) argued that the level the members of the institution supports the usage of an innovation is associated positively with the success 
of implementation. Klein et al. (2001) believed implementing organisations' climate should be different from satisfactions of members of an organisation or appraising the innovation itself

Klein past argument was supported by Rivard, Lapointe, and Kappos (2011) who argued that due to the different levels of operations of the organisation, implementing the measurement of organisation's climate can be very difficult which needs the survey of multi-dimensional perception data from potential end-users of the innovation in the organisation. However, Noor and Dzulkifli $(2012,2013)$ indicated that studies of organisations' climate role in innovations shows mixed results.

\subsubsection{Top Management Style}

The process of adoption can influence implementation positively or negatively (Pinto and Slevin, 1987). Top managements are to decide if an innovation will be adopted or not. King (2002) argued that in times of change, the role of leadership is very key because a project needs commitment at the level of an organisation to succeed. Ke and Wei (2006) argued that leaders at the top will always assists in getting end-users support in implementing a dynamic system.

\subsubsection{Innovation Efficacy}

Peansupap and Walker (2005) in support of Rogers' (2003) model, contented that end-user's perception of ICTbased innovation is important when implementing ICT-based innovation. Thus, an ICT-based innovation should be subject to trials as well as users friendly so that end-users feel the need to use it. Finally, the relevancy of the ICT-based innovation to the section being implemented should be considered seriously.

\section{Methodology}

This study employed multistage sampling technique. The first stage involved the selection of three states, Lagos, Ogun and Oyo States in Southwestern Nigeria. The second stage is the selection of ten registered Primary Healthcare Centres in each state. The third stage is the selection of the centre Apex head (Medical Officer of Health) and six heads of department (these are Chief Nursing Officers, Nursing Officers, Community Health Extension Workers, Community Health Officers, Health Officers and Community Doctors) per centre per state. Thus, a total of 210 respondents participated in the study. Lagos State was chosen due to the 57 number of Local Council Development Areas (LCDA) in the state thus leading to primary healthcare centres located in each LCDA as registered with the state primary healthcare board.

This result is supported by Eshofonie, (2008) who stated that Lagos is a relatively 'built - up 'environment with many infrastructures like government establishments, and all kinds of private developments, such as schools, hospitals, and primary healthcare centres to mention a few. This same structure exists in Ogun and Oyo state and because of the creation of LCDA in the state, it has also influenced the number of primary healthcare centres located in each LCDA in the state. Another factor is that the government invest more budgetary resource to the states chosen in the Southwestern Nigeria. Data were obtained using two sets of questionnaires as well as interviews. The first set of questionnaires was administered on the heads of primary healthcare centres while the second set was administered on the heads of department. The first set elicits information on ICT-based innovations introduced in the past three years. The second set of questionnaire elicits information on the extent and level of adoption of the ICT-based innovations in the primary healthcare centres. Secondary data such as directory showing number and location of primary healthcare centres were sourced from the reports of Primary healthcare Board. Data obtained were analyzed using appropriate descriptive statistics such as frequency count, percentage, cross-tabulation etc. and inferential statistics such as factor analysis.

\section{Results and Discussion}

In table 1, 198 survey responses which represent $94.3 \%$ out of the expected 210 survey respondents were retrieved completely and used for the study in addition to interviews conducted.

According to Gendall (2000), since achieving a response rate of $60 \%$ or more was possible, then it would be in place to regard $50 \%$ rate of response in research survey as a minimum acceptable threshold. This position by Gendall (2000) was averred by Nulty (2008), Net (2009) and Schmid et al. (2012) who argued that although a 60\% rate of response was desirous and can be achieved in survey research, a $50 \%$ rate of response was acceptable. Therefore the $94.3 \%$ rate of response in this study can be concluded to be considered as acceptable since it met the minimum threshold set.

\begin{tabular}{|c|c|c|c|c|c|c|c|}
\hline \multirow[t]{3}{*}{ State } & \multirow{3}{*}{$\begin{array}{c}\text { No. of } \\
\text { Primary } \\
\text { Healthcare } \\
\text { Centres (\%) }\end{array}$} & \multicolumn{6}{|c|}{ Number of Respondents } \\
\hline & & \multicolumn{2}{|c|}{ Head of Centres } & \multicolumn{2}{|c|}{ Health Workers } & \multicolumn{2}{|c|}{ Total } \\
\hline & & $\begin{array}{c}\text { Distributed } \\
(\%)\end{array}$ & $\begin{array}{c}\text { Retrieved } \\
\text { (\%) }\end{array}$ & $\begin{array}{c}\text { Distributed } \\
(\%)\end{array}$ & $\begin{array}{c}\text { Retrieved } \\
\text { (\%) }\end{array}$ & $\begin{array}{c}\text { Distributed } \\
\text { (\%) }\end{array}$ & $\begin{array}{c}\text { Retrieved } \\
\text { (\%) }\end{array}$ \\
\hline Lagos & $10(33.3)$ & $10(4.7)$ & $10(4.7)$ & $60(28.6)$ & $54(25.8)$ & $70(33.3)$ & $64(30.5)$ \\
\hline Ogun & $10(33.3)$ & $10(4.7)$ & $10(4.7)$ & $60(28.6)$ & $57(27.2)$ & $70(33.3)$ & $67(31.9)$ \\
\hline Оуо & $10(33.3)$ & $10(4.7)$ & $10(4.7)$ & $60(28.6)$ & $57(27.2)$ & $70(33.3)$ & 67 (31.9) \\
\hline Total & $30(100)$ & $30(14.1)$ & $30(14.1)$ & $180(85.8)$ & $168(80.2)$ & $210(100)$ & $198(94.3)$ \\
\hline
\end{tabular}




\subsection{Factors Influencing the Implementation of ICT-Based Innovations}

Table 2 revealed that majority (87.4\%) of the respondents' rated Management support to be a very important factor that influenced the implementation of ICT-based Innovations in the primary healthcare centres. This means that without management support of any ICT-based innovation, it cannot be implemented in the primary healthcare centre. Interviews revealed that it is the primary healthcare board of different States that regulate the operations of the primary healthcare centres in a State and any ICT-based innovation not endorsed and approved by the board of a State cannot be introduced for adoption or implementation by the primary healthcare centres in any local government area (LGA) or local council development area (LCDA) in the State. This agrees with the reports of Weiner et al. (2009) that the management support of an organizations is the sole authority that decides if an ICT-based innovation is to adopted in an organisation or not. However, Chaudhry (2006) noted that the outcome of ICT-based innovation funding still depends on the capacity and capability of the organisation to implement and sustain those funding's.

\begin{tabular}{|c|c|c|c|c|c|}
\hline Factors & $\mathbf{5}$ & $\mathbf{4}$ & $\mathbf{3}$ & $\mathbf{2}$ & $\mathbf{1}$ \\
\hline Organizational readiness for change & $145(73.2)$ & $51(25.8)$ & $2(1.0)$ & & \\
\hline Financial resource availability & $114(57.6)$ & $76(38.4)$ & $4(2.0)$ & $3(1.5)$ & $1(0.5)$ \\
\hline Management support & $173(87.4)$ & $20(10.1)$ & $2(1.0)$ & $3(1.5)$ & \\
\hline Training & $155(78.3)$ & $38(19.2)$ & $4(2.0)$ & $1(0.5)$ & \\
\hline Organizational maturity & $130(65.7)$ & $59(29.8)$ & $8(4.0)$ & $1(0.5)$ & \\
\hline Patient demand & $136(68.7)$ & $44(22.2)$ & $15(7.6)$ & $3(1.5)$ & \\
\hline Leadership decision & $112(56.6)$ & $72(36.4)$ & $14(7.1)$ & & \\
\hline Timing & $62(31.3)$ & $131(66.2)$ & $5(2.5)$ & & \\
\hline Regulatory agencies & $97(49.0)$ & $81(40.9)$ & $18(9.1)$ & $2(1.0)$ & \\
\hline Cost of operation & $116(58.6)$ & $74(37.4)$ & $4(2.0)$ & $4(2.0)$ & \\
\hline Safety & $160(80.8)$ & $31(15.7)$ & $6(3.0)$ & & $1(0.5)$ \\
\hline Need to improve efficiency & $136(68.7)$ & $58(29.3)$ & $4(2.0)$ & & \\
\hline Power & $135(68.2)$ & $18(9.1)$ & $44(22.2)$ & & $1(0.5)$ \\
\hline Patient satisfaction & $126(63.6)$ & $41(20.7)$ & $30(15.2)$ & $1(0.5)$ & \\
\hline Mortality rate & $119(60.1)$ & $41(20.7)$ & $17(8.6)$ & $17(8.6)$ & $4(2.0)$ \\
\hline Disease outbreak & $106(53.5)$ & $50(25.3)$ & $16(8.1)$ & $20(10.1)$ & $6(3.0)$ \\
\hline Relative advantage & $110(55.6)$ & $73(36.9)$ & $9(4.5)$ & & $6(3.0)$ \\
\hline Compatibility & $142(71.7)$ & $36(18.2)$ & $19(9.6)$ & & $1(0.5)$ \\
\hline Ease of use & $119(60.1)$ & $46(23.2)$ & $31(15.7)$ & $2(1.0)$ & \\
\hline Complexity & $131(66.2)$ & $30(15.2)$ & $14(7.1)$ & $22(11.1)$ & $1(1.0)$ \\
\hline New Technology & $130(65.7)$ & $55(27.8)$ & $10(5.1)$ & $2(1.0)$ & $1(0.5)$ \\
\hline Trialability & $96(48.5)$ & $89(44.9)$ & $11(5.6)$ & $1(0.5)$ & $1(0.5)$ \\
\hline Observability & $103(52.0)$ & $64(32.3)$ & $30(15.2)$ & $1(0.5)$ & \\
\hline Communicability & $95(48.0)$ & $79(39.9)$ & $5(2.5)$ & $19(9.6)$ & \\
\hline Job relevance & $75(37.9)$ & $98(49.5)$ & $25(12.6)$ & & \\
\hline Applicability & $145(73.2)$ & $28(14.1)$ & $6(3.0)$ & $19(9.6)$ & \\
\hline Divisibility & $114(57.6)$ & $58(29.3)$ & $7(3.5)$ & $19(9.6)$ & \\
\hline Social approval & $91(46.0)$ & $101(51.0)$ & $4(2.0)$ & $2(1.0)$ & \\
\hline a & $9.05)$ &
\end{tabular}

Table 2: Descriptive Statistics of Factors Influencing the Implementation of ICT-Based Innovations

5 - Very Important, 4 - Important, 3 - Moderately Important, 2 - Slightly Important,

$$
1 \text { - Not Important }
$$

Note: Figures in Parentheses Are Row Percentages

That might suggest the reason effective implementation of ICT-based innovation in any organisation is determined greatly by top management support (Maditinos et al., 2012).

Eighty percent of the respondents indicated safety as the second most important factor that influenced the implementation of ICT-based Innovations in the selected primary healthcare centres. This suggests that new ICT-based innovations are safer to use by the respondents on those who visit the primary healthcare centres than the old conventional methods. About $78 \%$ of the respondent rated training as the third most important factor that influenced the implementation of ICT-based Innovations in the primary healthcare centres. Interviews revealed that the regular training of the head of healthcare centres and health workers by the primary healthcare board exposed health workers to new ICTbased innovations and how it works during the training. It means continuous training will influence the implementation of ICT-based Innovations in the primary healthcare centres.

\subsection{Factor Analysis}

Factors that influence implementation of ICT-based Innovations in the primary healthcare sector in the study area were determined empirically by employing factor analysis to reduce the twenty-eight data to form more meaningful validated constructs as described in related literature using principal component analysis. The variables' co-variance was computed to determine the number of factors to be used in rotation. The computed data were thereafter transformed into factors after evaluating the variance Eigen value and Eigen vectors co-variance matrix. The following were the results of 
the factor analysis. Kaiser-Meyer-Olkin (KMO) analysis was the first statistics used to measure samples as presented in Table 3

\begin{tabular}{|c|c|c|c|}
\hline $\begin{array}{c}\text { Kaiser-Meyer-Olkin (KMO) Measure } \\
\text { of Sampling Adequacy. }\end{array}$ & $\begin{array}{c}\text { Bartlett's Test of Sphericity } \\
\text { Approx. Chi-Square }\end{array}$ & Df & Sig. \\
\hline 0.71 & 6189 & 378 & 0.000 \\
\hline
\end{tabular}

Table 3: Kaiser-Meyer-Olkin Measure of Sampling Adequacy on Factors Influencing the Implementation of ICT-Based Innovation

Adequacy on factors influencing the implementation of ICT-based innovation in primary healthcare centres and the Bartlett test of sphericity tests for the assumption that the variables are not correlated. PCA requires that the probability associated with Bartlett's test of sphericity be less than the level of significance. In this study, the probability associated with the Bartlett's test is less than 0.001 which satisfies the PCA requirement. From the results, 0.712 value was obtained from the KMO, which was higher than 0.5 threshold. This indicates that principal component analysis was appropriate for the data. Yil and Yil (2009) argued that for factor analysis to fit perfectly, a higher KMO value is preferred because the data will yield reliable and distinct factors when the value of the KMO is close to 1. Similarly, Bartlett's test that the original correlation matrix is an identity matrix indicates a highly significant $(p<0.000)$, and therefore factor analysis is appropriate for the data.

\subsection{Total Variance Explained by Retained Components}

Table 4 depicts the Eigen value table divided into three sub-sections, i.e. Initial Eigen Values, Extracted Sums of Squared Loadings and Rotation of Sums of Squared Loadings. The Eigen values associated with each factor represent the variance explained by that particular linear component in terms of the percentage of variance explained (so factor 1 explains $37.142 \%$ of total variance) while subsequent factors explain only small amounts of variance. The table further shows that all factors with Eigen values greater than 1 are extracted, which leaves 7 factors. However, the Eigen values associated with these factors are again displayed.

Total variance explained helps in showing which components to include in factor solution. It also shows the cumulative percentage of loadings on the retained components. From Table 4, only the first seven components displayed eigenvalues greater than 1 . The first component extracted in a principal component analysis accounts for $18.619 \%$ of total variance in the observed variables. The second component extracted accounts for $12.101 \%$ of variance in the data set that was not accounted for by the first component. The cumulative percentage of the seven components is $79.179 \%$ of the total variance. The results suggest that only the first seven components were meaningful and thus only the first seven components were retained for rotation.

\begin{tabular}{|c|c|c|c|c|c|c|c|c|c|}
\hline \multirow[t]{2}{*}{ Component } & \multicolumn{3}{|c|}{ Initial Eigen Values } & \multicolumn{3}{|c|}{$\begin{array}{l}\text { Extraction Sums of } \\
\text { Squared Loadings }\end{array}$} & \multicolumn{3}{|c|}{$\begin{array}{c}\text { Rotation Sums of Squared } \\
\text { Loadings }\end{array}$} \\
\hline & 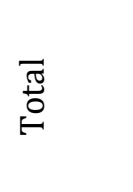 & 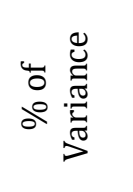 & 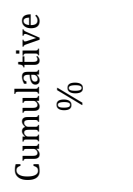 & त्ञ & 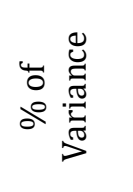 & 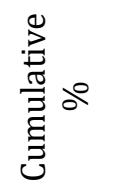 & 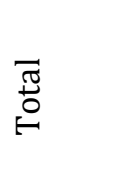 & 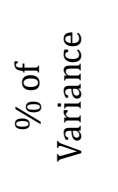 & 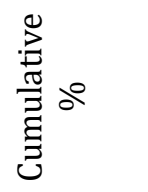 \\
\hline 1 & 10.400 & 37.142 & 37.142 & 10.400 & 37.142 & 37.142 & 5.213 & 18.619 & 18.619 \\
\hline 2 & 3.135 & 11.195 & 48.337 & 3.135 & 11.195 & 48.337 & 3.388 & 12.101 & 30.720 \\
\hline 3 & 2.533 & 9.046 & 57.383 & 2.533 & 9.046 & 57.383 & 3.056 & 10.916 & 41.636 \\
\hline 4 & 1.890 & 6.748 & 64.131 & 1.890 & 96.748 & 64.131 & 3.008 & 10.744 & 52.379 \\
\hline 5 & 1.636 & 5.843 & 69.974 & 1.636 & 5.843 & 69.974 & 2.962 & 10.577 & 62.957 \\
\hline 6 & 1.422 & 5.078 & 75.052 & 1.422 & 5.078 & 75.052 & 2.451 & 8.753 & 71.709 \\
\hline 7 & 1.156 & 4.127 & 79.179 & 1.156 & 4.127 & 79.179 & 2.092 & 7.470 & 79.179 \\
\hline 8 & .930 & 3.321 & 82.500 & & & & & & \\
\hline 9 & .870 & 3.108 & 85.608 & & & & & & \\
\hline 10 & .666 & 2.378 & 87.986 & & & & & & \\
\hline 11 & .528 & 1.886 & 89.871 & & & & & & \\
\hline 12 & .468 & 1.673 & 91.544 & & & & & & \\
\hline 13 & .392 & 1.400 & 92.944 & & & & & & \\
\hline 14 & .373 & 1.332 & 94.276 & & & & & & \\
\hline 15 & .314 & 1.121 & 95.396 & & & & & & \\
\hline 16 & .226 & .809 & 96.205 & & & & & & \\
\hline 17 & .219 & .781 & 96.986 & & & & & & \\
\hline 18 & .174 & .623 & 97.609 & & & & & & \\
\hline 19 & .159 & .567 & 98.176 & & & & & & \\
\hline 20 & .110 & .392 & 98.568 & & & & & & \\
\hline
\end{tabular}




\begin{tabular}{|c|c|c|c|c|c|c|c|c|c|}
\hline \multirow[t]{2}{*}{ Component } & \multicolumn{3}{|c|}{ Initial Eigen Values } & \multicolumn{3}{|c|}{$\begin{array}{l}\text { Extraction Sums of } \\
\text { Squared Loadings }\end{array}$} & \multicolumn{3}{|c|}{$\begin{array}{c}\text { Rotation Sums of Squared } \\
\text { Loadings }\end{array}$} \\
\hline & $\underset{\pi}{\overparen{\pi}}$ & 范 & $\sum_{3}^{0}$ & $\stackrel{7}{\stackrel{\pi}{0}}$ & 范 & $\underbrace{0}_{3}$ & $\stackrel{\pi}{\stackrel{\pi}{0}}$ & 苞 & $\underbrace{0}_{3} \overbrace{}^{0}$ \\
\hline 21 & .093 & .333 & 98.901 & & & & & & \\
\hline 22 & .077 & .274 & 99.175 & & & & & & \\
\hline 23 & .065 & .231 & 99.407 & & & & & & \\
\hline 24 & .054 & .192 & 99.599 & & & & & & \\
\hline 25 & .040 & .144 & 99.742 & & & & & & \\
\hline 26 & .037 & .130 & 99.873 & & & & & & \\
\hline 27 & .023 & .082 & 99.955 & & & & & & \\
\hline 28 & .013 & .045 & 100.000 & & & & & & \\
\hline
\end{tabular}

Table 4: Total Variance Explained on Factors Influencing the Implementation of ICT-Based Innovation in Primary Health

Figure 2 indicates that the screen plot with a thunderbolt indicating the point of inflexion on the curve. This curve shows that a stable plateau was reached after factor 7. This justify retaining factor 1 to 7 .

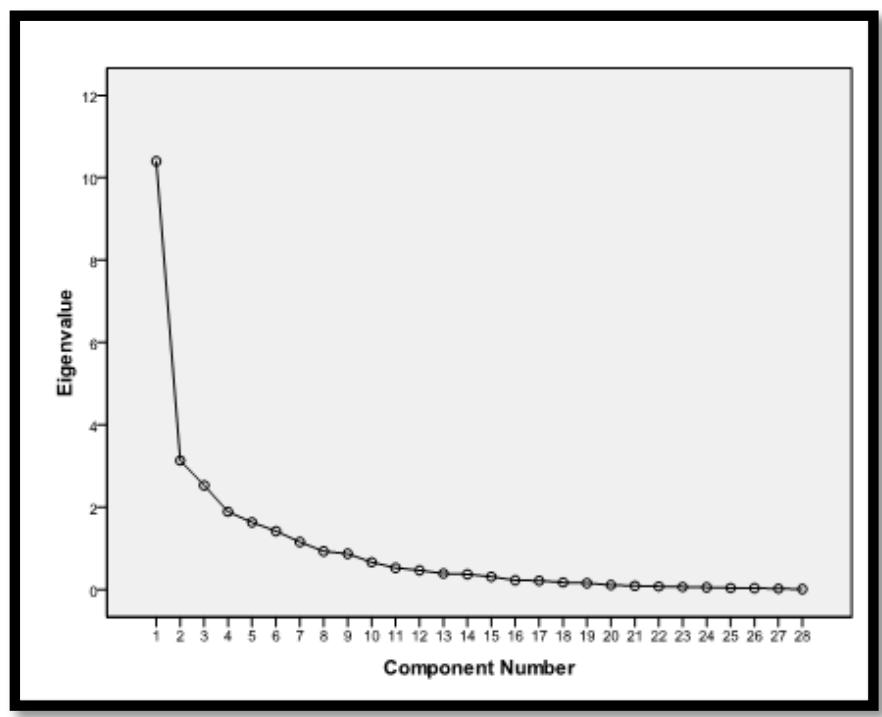

Figure 2: Screen Plot on Factors Influencing the Implementation of ICT-Based Innovation in Primary Health

\subsection{Rotated Component Matrix on Factors Influencing the Implementation of ICT-based Innovation in Primary Health}

Table 5 shows the extracted values of each item under the 7 variables of the twenty-eight variables on the seven factors extracted. The higher the absolute value of the extracted values, the more the factor contributes to the variable (We have extracted seven variables wherein the 28 items are divided into 7 variables according to most important items which similar responses in component 1 and simultaneously in component 2, 3, 4, 5, 6 and 7). The gap (empty spaces) on the table represent extracted values that are less than 0.5 , this makes reading the table easier. We suppressed all extracted values less than 0.5 in Table 4.17 .

The aim of rotation is to reduce the number factors on which the variables under investigation have high extracted values. Rotation does not actually change anything but makes the interpretation of the analysis easier.

The factor extracted values displayed in the component matrix in Table 5 shows the statistical pattern in the variables. It is used to show which sets of variables in the selected group of variables form coherent subsets that are relatively independent of one another. Interpretation of the principal components is based on finding which variables are most strongly correlated with each component, that is, which of these numbers are large in magnitude, the farthest from zero in either direction. Which numbers we consider to be large or small is of course is a subjective decision. One needs to determine at what level the correlation is of importance. Here a correlation above 0.5 is deemed important. 


\begin{tabular}{|c|c|c|c|c|c|c|c|c|}
\hline & \multicolumn{9}{|c|}{ Component } \\
\hline $\mathbf{S / N}$ & Factors & $\mathbf{1}$ & $\mathbf{2}$ & $\mathbf{3}$ & $\mathbf{4}$ & $\mathbf{5}$ & $\mathbf{6}$ & $\mathbf{7}$ \\
\hline 1 & Applicability & .848 & & & & & & \\
\hline 2 & Communicability & .845 & & & & & & \\
\hline 3 & job relevance & .809 & & & & & & \\
\hline 4 & Divisibility & .748 & & & .504 & & & \\
\hline 5 & Observability & .639 & .502 & & & & & \\
\hline 6 & $\begin{array}{c}\text { organisational readiness } \\
\text { for change }\end{array}$ & .475 & .425 & & & & & \\
\hline 7 & need to improve efficiency & & .834 & & & & & \\
\hline 8 & Financial resource & & .774 & & & & & \\
\hline 9 & availability & & & & & & & \\
\hline 10 & management support & & .486 & & & .443 & & \\
\hline 11 & disease outbreak & .479 & & .796 & & & & \\
\hline 12 & mortality rate & & & .683 & & & .491 & \\
\hline 13 & patient satisfaction & .508 & & .634 & & & & \\
\hline 14 & Trialability & & & & .745 & & & \\
\hline 15 & new technology & & & & .635 & & & \\
\hline 16 & social approval & & & & .610 & .410 & & \\
\hline 17 & organisational maturity & & .447 & & .566 & & & \\
\hline 18 & patient demand & & .422 & & .484 & & & \\
\hline 19 & Compatibility & & & & & .799 & & \\
\hline 20 & Safety & & & & & .645 & & \\
\hline 21 & Training & & & & & .626 & & \\
\hline 22 & ease of use & & & .442 & & .557 & & \\
\hline 23 & leadership decision & & & & & & .808 & \\
\hline 24 & Complexity & & & & & .426 & .645 & \\
\hline 25 & regulatory agencies & & .526 & & & & .601 & \\
\hline 26 & Timing & & .475 & & & & .480 & \\
\hline 27 & Power & & & & & & & .825 \\
\hline 28 & cost of operation & & & & & & & .550 \\
\hline & \%of Variance & 37.142 & 11.195 & 9.046 & 6.748 & 5.843 & 5.078 & 4.127 \\
\hline
\end{tabular}

Table 5: Rotated Component Matrix on Factors Influencing the Implementation of ICT-Based Innovation in Primary Health

Technically, a factor (or component) represents whatever its variables have in common. Rotated component matrix in Table 5 shows that our first component is measured by applicability, communicability, job relevance, divisibility, observability and patient satisfaction which relate to the respondent ability to communicate clearly using the ICT-based innovation. Therefore, we interpret component 1 as "clarity of usage".

Component1 (clarity of usage): The first principal component is strongly correlated with six of the original variables. The first principal component increases with increasing applicability, communicability, job relevance, divisibility, observability and patient satisfaction of the implementation of ICT-Based innovation in primary health. This suggests that these six criteria vary together. If one increases, then the remaining ones tend to increase as well. This component can be viewed as a measure of the quality of applicability, communicability, job relevance, divisibility, observability and patient satisfaction. More so, based on the correlation of $0.848,0.845$ and 0.809 , component 1 "clarity of usage" is primarily measure of the applicability, communicability, job relevance. This suggests that clarity of usage component influence the implementation of ICT-Based innovation in primary healthcare delivery in Southwestern Nigeria.

The second component is measured by observability, need to improve efficiency, financial resource availability and regulatory agencies which relate to the respondent receiving clear policy on the usage of the ICT-based innovation. Component 2 can therefore be interpreted as "clarity of policy".

Component2 (clarity of policy): This component increases with four of the original variables. This second component increases as observability, need to improve efficiency, financial resource availability and regulatory agencies. Component 2 is a primarily measure of the need to increase efficiency because of the strong correlation it has with the clarity of policy.

The third component is measured by relative advantage, disease outbreak, mortality rate and patient satisfaction which relate to the respondent avoiding loss of lives by using the ICT-based innovation.

Component 3 can be interpreted therefore as "protecting lives". Component 3 (Protecting Lives): Four (relative advantage, disease outbreak, mortality rate and patient satisfaction) increase component 3 . In other word, this component can be seen as a measure of relative advantage, disease outbreak, mortality rate and patient satisfaction.

The fourth component is measured by divisibility, trialability, new technology, social approval and organizational maturity which relate to the respondent receiving clarity of Acceptance to use the ICT-based innovation easily. Component 4 can be interpreted therefore as "clarity of Acceptance". 
Component 4 (clarity of Acceptance): The fourth principal component is correlated with five of the original variables. The fourth principal component increases with increasing divisibility, trialability, new technology, social approval and organizational maturity. An innovation classified as simple to use quickly gains acceptance due to its ease of use and is promptly adopted (Rogers, 2003).

The fifth component is measured by compatibility, safety, training and ease of use which relate to the respondent receiving quality from the ICT-based innovation. Component 5 can be interpreted therefore as "quality".

Component5 (quality): The fifth principal component is correlated with four of the original variables. The principal component increases with increasing compatibility, safety, training and ease of use. This suggests that these four criteria vary together. If one increases, then the remaining ones tend to increase as well. This component can be viewed as a measure of the quality of compatibility, safety, training and ease of use of the ICT-Based innovation in Primary health.

The sixth component is measured by leadership decision, complexity and regulatory agencies which relate to the respondent receiving authority to use the ICT-based innovation. Component 6 can be interpreted therefore as "Authority".

Component 6 (Authority): The sixth principal component is correlated with three of the original variables, the variables are leadership decision, complexity and regulatory agencies. This implies that if one increases, the remaining two tends to increase as well. Also, based on the correlation of 0.808 , component 6 "??" is primarily measure of the leadership decision.

The seventh component is measured by Power and cost of operation which relate to the respondent energy requirement to run the ICT-based innovation. Component 7 can be interpreted therefore as "energy requirement".

Component 7 (energy requirement): Power and cost of operation are correlated with the component 7 . Component 7 increases with increasing power and cost of operation of the ICT-based innovation in primary health.

This allows us to conclude that "clarity of usage" is rated best factor that Influence the Implementation of ICTbased Innovation in Primary Health and "energy requirement" is rated worst factor that Influence the Implementation of ICT-based Innovation in Primary Health in Southwestern Nigeria.

All the seven (7) component factors Clarity of Usage, Clarity of Policy, Protecting lives, Clarity of Acceptance, Quality, Authority, Energy Requirement identified in the analysis to influence the implementation of ICT-based innovation in Southwestern Nigeria is represented in Figure 3.

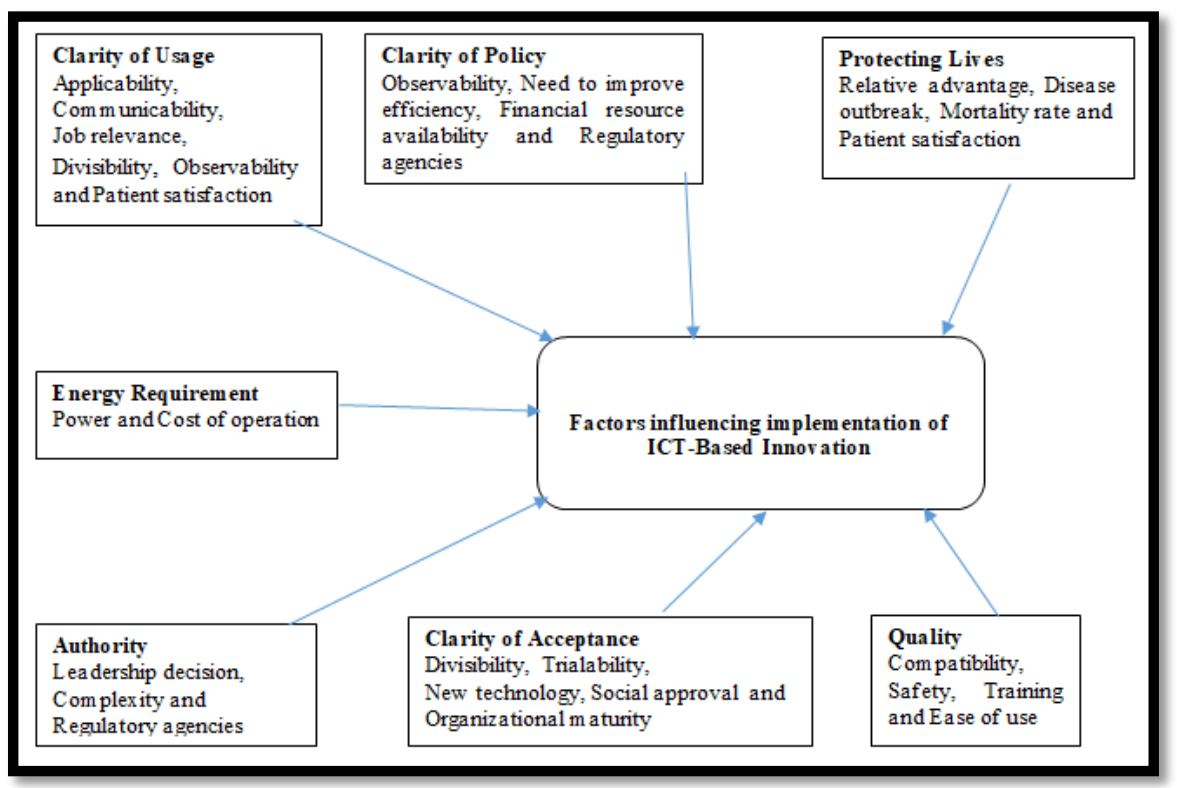

Figure 3: Grouped Factors Influencing Implementation of ICT-Based Innovation

\section{Conclusion}

The study shows that 7 grouped extracted component factors were discovered to influence the implementation of ICT-based innovation in Southwestern Nigeria. These component factors are clarity of usage, clarity of policy, protecting lives, clarity of acceptance, quality, authority, and energy. The study concluded that implementation of ICT-based innovations in the Nigerian primary healthcare sector would be enhanced if the component factors highlighted could be considered for adoption for future ICT-based innovation implementation

\section{Policy Recommendation}

The Primary Healthcare Boards of different States should continue to organize regular training through workshop and refresher courses to equip healthcare professionals with the necessary basic skills needed in operating new ICT-based innovation. 


\section{References}

i. Chaudhry, B. (2006). Systematic review: impact of health information technology on quality, efficiency, and costs of medical care. Annals of Internal Medicine, 144(10), 742-752.

ii. Gendall, P. (2000). Responding to the problem of nonresponse. Australasian Journal of Market Research, 8(1), 317.

iii. Ika, L. A., Diallo, A., and Thuillier, D. (2010). Project management in the international industry: The project coordinator's perspective. International Journal of Managing Projects in Business, 3(1), 61-93

iv. Ke, W. L. and Wei, K. K. (2006). Organizational learning process: Its antecedents and consequences in enterprise system implementation, Journal of Global Information Management, 14(1), 1-22.

v. King, P. (2002). The implementation of technology-based information systems: Analysing and influencing success (Doctoral dissertation submitted 2002).

vi. Klein, K. J., and Sorra, J. S. (1996). The challenge of innovation implementation. Academy of Management Review, 21(4), 1055-1079.

vii. Klein, K., Conn, A. B., and Sorra, J. S. (2001). Implementing computerized technology: An organizational analysis. Journal of Applied Psychology, 86(5), 811-824.

viii. Kwak, N. and Radler, B. A. (2002). A comparison between mail and Web surveys: Response pattern, respondent profile, and data quality. Journal of Official Statistics, 18(2), 257-273.

ix. Macharia, J. and Nyakwende, E. (2010). Vice-chancellors' influence on academic staff intentions to use learning management systems (LMS) for teaching and learning. The Journal of Language, Technology \& Entrepreneurship in Africa, 2(1).

X. Maditinos, D., Chatzoudes, D., \& Tsairidis, C. (2012). Factors affecting ERP system implementation effectiveness. Journal of Enterprise Information Management (JEIM), 25(1), 60-78. ISSN 1741-0398, Emerald. doi:10.1108/17410391211192161. Electronic publication at:

http://www.emeraldinsight.com/journals.htm?articleid=17004132\&show=pdf, last accessed 20 th June 2016.

xi. Montgomery, N. and Zint, M. (2010). Evaluation: What is it and why do it? Available online: http://meera.snre.umich.edu/pla last accessed 3rd November 2018

xii. Net, F. P. (2009). Combining Web-based and mail surveys improves response rates: A PBRN study, $245-249$. doi:10.1370/afm.944.

xiii. Ng'ethe (2003). Higher education innovations in Sub-Saharan Africa: With specific reference to universities. Available online: http://www.aau.org/wghe/publications/wghe_innovations_ref_univ.pdf. last accessed 22nd October 2016

xiv. Noor, H. M and Dzulkifli, B. (2013). Assessing leadership practices, organizational climate and its effect towards innovative work behaviour in R\&D. International Journal of Social Science and Humanity, 3(2), 129-133. doi:10.7763/IJSSH.2013.V3.211

xv. Noor, H. M. and Dzulkifli, B., (2012). Assessing the organizational climate towards developing innovative work behavior: A literature review. 3rd International Conference on Business and Economic Research (3rd Icber 2012) Proceeding 12-13 March 2012 (pp. 1487-1497). Retrieved from:

http://www.internationalconference.com.my/proceeding/3rd_icber2012_proceeding/101_313_3rdICBER2012_ Proceeding_PG1487_1497.pdf. last accessed 21st April 2016.

xvi. Nulty, D. D. (2008). The adequacy of response rates to online and paper surveys: What can be done? Assessment \& Evaluation in Higher Education, 33(3), 301-314. doi:10.1080/02602930701293231

xvii. Olakunde, O. B. (2012) Public health care financing in Nigeria: Which way forward? Ann Nigerian Med [Internet]; 6: 4-10. Available from: http://www.anmjournal.com/text.asp?2012/6/1/4/100199. [10 May 2018, date last accessed].

xviii. Osei-Bryson, K., Dong, L., and Ngwenyama, O. (2008). Exploring managerial factors affecting ERP implementation: An investigation of the Klein-Sorra model using regression splines. Information Systems Journal, 18, 499-527.

xix. Peansupap, V. and Walker, D. (2005), Factors enabling information and communication technology diffusion and actual implementation in construction firms, Electronic Journal of Information Technology in Construction,10( 14), 193-218

xx. Peng, F. and Kurnia, S. (2010). Understanding hospital information systems adoption in China (2010). Pacific Asia Conference on Information Systems 2010 Proceedings. Pp 66.

xxi. Pinto, J. K. and Slevin, D. P. (1987). Critical factors in successful project implementation. IEEE Transactions on Engineering Management, 4(1), 22-28.

xxii. Rivard, S., Lapointe, L., and Kappos, A. (2011). An organizational culture-based theory of clinical information systems implementation in hospitals. Journal of the Association for Information Systems, 12(2).

xxiii. Rogers, E. M. (2003). Diffusion of Innovations. 5th Edition. Simon and Schuster. New York: Free Press.

xxiv. Rogers, E. M. (2003). Diffusion of Innovations. 5th Edition. Simon and Schuster. New York: Free Press.

xxv. Sawang, S. and Unsworth, K. (2011). A model of organizational innovation implementation effectiveness in small to medium firms. International Journal of Innovation Management, 15(5), 989-1011. Available online: http://ssrn.com/abstract=2168595 or http://dx.doi.org/10.2139/ssrn. 2168595, last accessed 15 th Aug 2012.

xxvi. Schmid, M., Steinlein, C., Bogart, J. P., Feichtinger, W., Haaf, T., Nanda, I., and Del Pino, E. M. (2012): Introduction. Cytogenetic and Genome Research, 138(2-4), 85-156. doi:10.1159/000207355. 
xxvii. Studer, M. (2005). The effect of organizational factors on the effectiveness of EMR system implementation What have we learned? Electronic Healthcare Journal, 4(2), 92-98. Available online:

http://www.medicexchange.com/pdf/EMR/effect-oforganizational-factors-on-the-effectiveness-of-emr-systemimplementation. pdf, last accessed 27th Jan 2016.

xxviii. Vaughan, P. (2001). System implementation success factors: It is not just the technology. Retrieved from: http://www.docjax.com/document/view.shtml?id=860464\&title=System $\% 20$ Implementation $\% 20$ Success $\% 20$ Factors:\%20It\%20Is\%20Not\%20Just\%20the\%20 Technology, last accessed 14th June 2016.

xxix. Weiner, B., Lewi, M. and Linnan, L. (2009). Using organization theory to understand the determinants of effective implementation of worksite health promotion programs. Health Education Research, 24(2), 292-305. 